University of Northern lowa

UNI ScholarWorks

Graduate Research Papers

Student Work

1998

\title{
Academic acceleration of gifted children
}

Lisa Moldenhauer

University of Northern lowa

Let us know how access to this document benefits you

Copyright (C)1998 Lisa Moldenhauer

Follow this and additional works at: https://scholarworks.uni.edu/grp

Part of the Curriculum and Instruction Commons, and the Gifted Education Commons

\section{Recommended Citation}

Moldenhauer, Lisa, "Academic acceleration of gifted children" (1998). Graduate Research Papers. 1220. https://scholarworks.uni.edu/grp/1220

This Open Access Graduate Research Paper is brought to you for free and open access by the Student Work at UNI ScholarWorks. It has been accepted for inclusion in Graduate Research Papers by an authorized administrator of UNI ScholarWorks. For more information, please contact scholarworks@uni.edu. 


\title{
Academic acceleration of gifted children
}

\begin{abstract}
The purpose of this paper is to examine academic acceleration. It looks at the rationale, different forms of acceleration, benefits, disadvantages, and guidelines that should be considered when accelerating. In addition, this paper examines teachers' beliefs and why they hold these beliefs concerning acceleration. Finally, the last chapter summarizes this study and draws conclusions from the literature and suggests recommendations for further study.
\end{abstract}


Academic Acceleration of Gifted Children

\author{
A Graduate Project \\ Submitted to the \\ Department of Curriculum and Instruction \\ In Partial Fulfillment \\ of the requirement for the Degree \\ Masters of Arts in Education \\ UNIVERSITY OF NORTHERN IOWA
}

by

Lisa Moldenhauer

June, 1998 
This Research Paper by: Lisa Moldenhauer

Entitled: Academic Acceleration of Gifted Children

has been approved as meeting the research requirement for Degree of Master of Arts in Education.
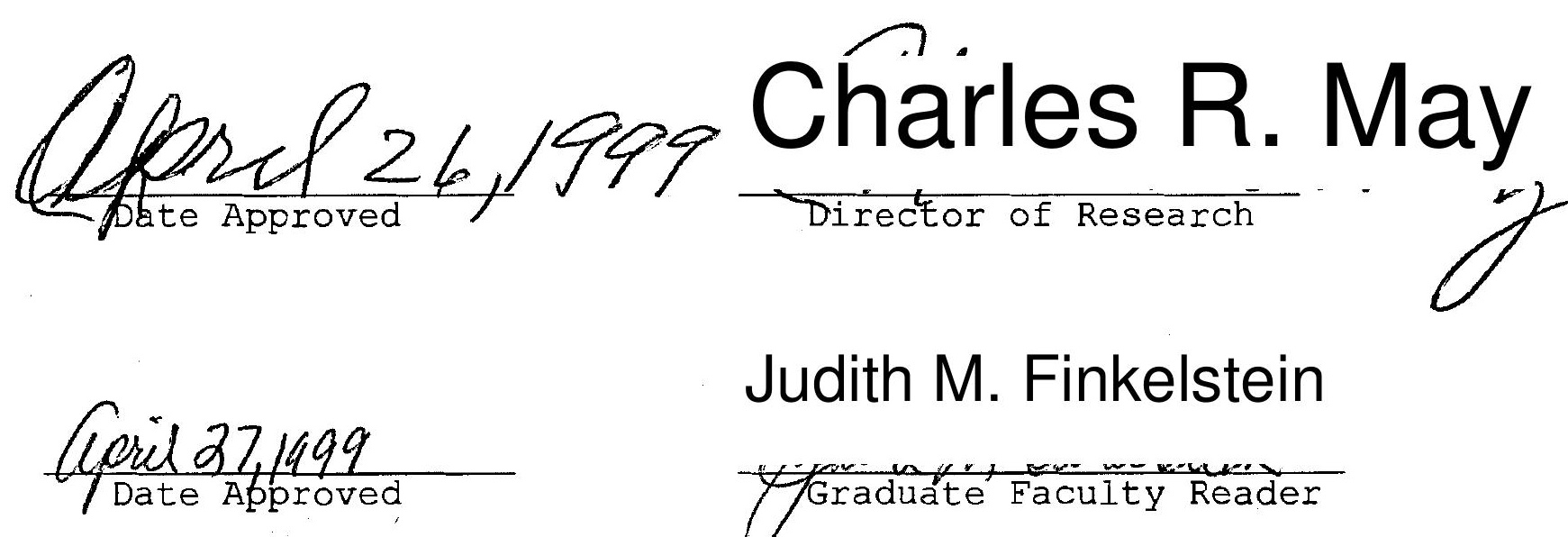

\section{Judith M. Finkelstein}

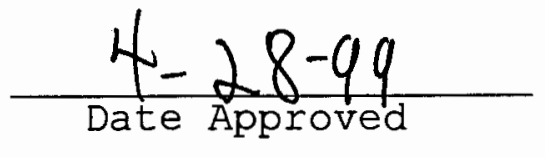

\section{W. P. Calahan}

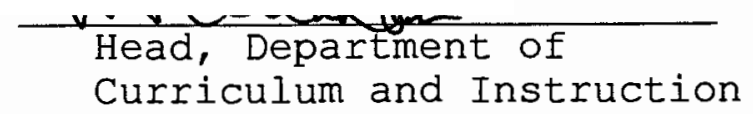




\section{ABSTRACT}

The purpose of this paper is to examine academic acceleration. It looks at the rationale, different forms of acceleration, benefits, disadvantages, and guidelines that should be considered when accelerating. In addition, this paper examines teachers' beliefs and why they hold these beliefs concerning acceleration. Finally, the last chapter summarizes this study and draws conclusions from the literature and suggests recommendations for further study. 


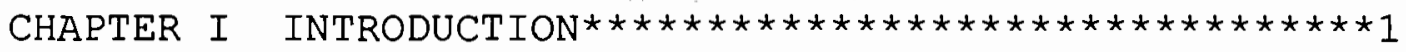

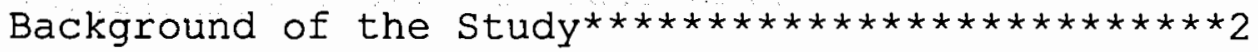

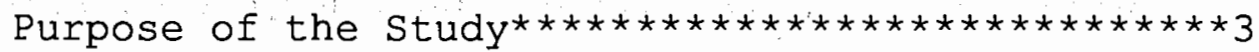

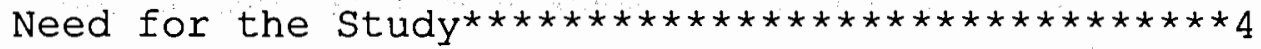

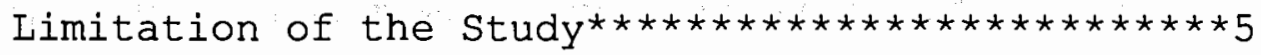

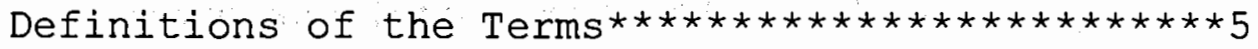

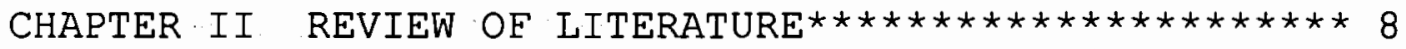

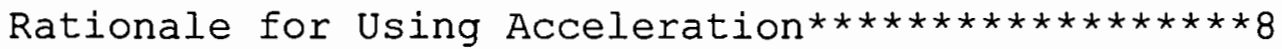
Different Forms of Acceleration $* \star \star \star \star * * * * \star * \star * * * * * * * 10$ Problems Involved in Using Acceleration $* \star \star \star * * * * * * 15$

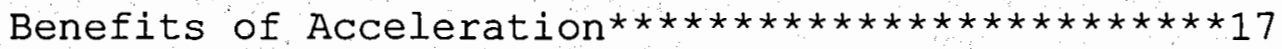

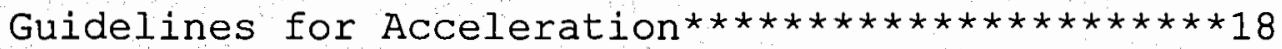

CHAPTER III SUMMARY, CONCLUSIONS AND

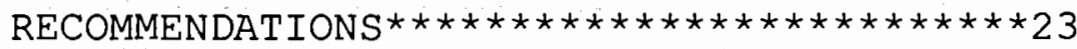

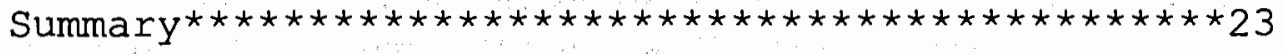

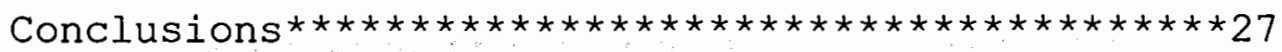

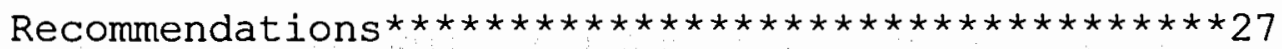


CHAPTER I

\section{INTRODUCTION}

For years, most educators have objected to letting unusually bright children skip a grade in school. The conventional wisdom was held that no matter how academically precocious children their social development would be hurt if children are moved out of their age group and into a more advanced class. But with more research showing those children suffer few, if any, social problems, educators are taking a new look at moving children ahead.

The literature in academic acceleration of young gifted children consistently demonstrates a lack of harmful effects. Both early admissions and later acceleration have been extensively studied, and no réliable researches exist that document harm. (Alexander and Skinner (1980), Considering that the body of literature spans five decades and has consistently associated the acceleration of precocious young children with positive changes, in their academic achievement and a lack of negative effects on social and emotional growth, one might conclude that the questions regarding the advisability of acceleration have been conclusively resolved (Southern, Jones, \& Fiscus, 1989 p.29).

Those who work with the gifted and talented say that, if handled carefully, skipping a grade can offer an educational boost for a very bright youngster. This has caused educators to look at acceleration, both advantages and disadvantages and its alternatives.

Educational acceleration as a curriculum option has been a divisive issue among educators since its first documented use in the st. Louis, 
Missouri, schools in 1862. As recently as 1988, Dorothy Sisk argued that acceleration may be the one practice that most directly circumvents boredom and underachievement. Despite little research to back up his contention, David Elkind, in a point-counterpoint debate with sisk, took exception to the term acceleration itself, alluding to potential social and dislocation problems that may occur when adults attempt to speed up a child's development. (Elkind 1988, Sisk 1988 p.58)

Early admission, another educational issue, has come into focus. Schools are evaluating policies of entrance date for children. Policies that once greatly decreased the probability that any students, including the academically precocious, will be offered early entrance.

\section{Background of the Study}

For gifted students to achieve at very high levels, grouping must be flexible and based on individual student needs. Also, careful organization is a necessary aspect of gifted programming. Csikszentmihalyi (1988) found that high IQ students were able to accomplish twice as many challenging tasks as average IQ students. Bloom (1985) observed that high-level talent development is nurtured through exposure to progressively more complex tasks. These tasks are organized on prestructured continuum of learning experience based upon mastery and readiness. This model for talent development was found effective regardless of talent domain (area of giftedness). Dweck and Elliot (1983) also demonstrated the relationship between positive. 
achievement and motivation and task difficulty at a challenging level (Van Tassel-Baska, 1992 p.69).

Principles of learning theory that we painstaking apply to other segments of the school population are not applied equally to the gifted. Concepts such as learning readiness, continuous progress, and challenge levels for learning are seen as important when designing curriculum for typical students. Yet, these concepts are in danger of becoming empty concepts unless educators develop meaning for the gifted as well. The gifted cannot be served appropriately until schools are willing to accelerate learning as needed by individuals and groups of gifted children.

\section{Purpose of the Study}

The purpose of this paper is to review the literature concerning academic acceleration, the benefits, problems and guidelines for acceleration in schools. In order to develop guidelines for an effective acceleration program the following questions will be addressed:

1. What is the rationale for using acceleration with gifted students?

2. What are the different forms of acceleration?

3. What are the problems involved in using acceleration?

4. What are the benefits of acceleration? 
5. What guidelines must be developed when considering a child for acceleration?

Need for the study

"Skipping grades was common in American schools until the 1920's. Now, this and other forms of academic acceleration, out of favor for half a century, seems poised for a comeback." (Wernick, July8, 1992 p. A17)

Today, a combination of factors is setting the stage for interest in acceleration. As school budgets tighten, programs for the gifted are being cut back, or eliminated. Tracking, or clustering, is another way to provide an enriched curriculum for gifted children; however, keeping gifted students together in one classroom is under attack by those who charge that grouping students by ability is undemocratic. At the same time, new research on acceleration has made converts among those who specialize in gifted education.

"Acceleration addresses the needs of gifted children," said Camella Person Benbow, Co-Director of the Office of Precollegiate Programs for Talented and Gifted at Iowa State University in a New York Times article (July 8,1992 p. A17). Benbow (1992) said "It saves money, because the child spends less time in school. And it is not like singling out gifted kids and sending them to an opera, which could benefit everyone." (Wernik, July 8, 1992 p. A17) Clearly a major contradiction exist between the policies of 
schools and the research on acceleration. There is a need to investigate all aspects of academic acceleration: advantages, disadvantages, alternatives, factors to consider when accelerating a child, and different forms of acceleration and how its used in the schools.

Because teachers and parents are heavily involved in the decision of acceleration, educators need to understand what factors, other than achievement or competence, influence teachers and parents when they decide whether or not to accelerate a child. The case of each student must be handled individually when it comes to acceleration.

\section{Limitations of the Study}

Due to time and availability of materials the literature reviewed for this study was mostly limited to materials available from the University of Dubuque, Clarke College, and Loras College libraries in Dubuque, Iowa. Materials and literature from the Dubuque Community School districts talent and gifted program was also used.

\section{Definition of Terms}

To have a clear understanding of this paper, the terms used in this paper will be defined in the following way:

Acceleration- is commonly used to denote models of both service delivery and curriculum delivery. 
Aptitudes-description of the abilities that constitute giftedness.

Enriched curriculum-refers to richer, more varied educational experiences, a curriculum that has been modified or added to in some way (Davis \& Rimm 1989; Howley, Howley, \& Pendarvis, 1986).

Enrichment-used to refer to curriculum as well as program delivery services.

Exceptionally gifted-children have an IQ range of 160-180. Gifted underachievers-students who appear to pose considerable intellectual potential but are performing in a mediocre fashion in the educational setting.

Giftedness-gifted and talented children are those identified by professionally qualified persons. The children by virtue of outstanding abilities, are capable of high performance. The demonstrated achievement and/or potential ability in any of the following areas singly or in combination: 1 . general intellectual ability; 2 . specific academic aptitude; 3 . creative or productive thinking; 4. leadership ability; 5. visual and performing arts; 6. psycho-motor ability.

Intelligence-an ability or set of abilities that permit an individual to solve problems or fashion products that are of consequences in a particular cultural setting. Moderately gifted-children have an IQ range of 140-160. 
Multiple intelligence-human cognitive competence is better described as a set of abilities, talents, or mental skills.

Profoundly gifted-children having an IQ of $180+$

Talent domain-areas of abilities in which you are gifted. 


\section{CHAPTER II}

\section{REVIEW OF LITERATURE}

One of the first questions that must be asked in any study of acceleration is the following: What is the rationale for using acceleration with gifted students?

\section{Rationale of Accelerated Programs}

Acceleration of the gifted fits well with our understanding of learning and developmental theories and research. There are numerous research studies which show that moving children ahead does not harm them. After surveying 70 years of research on the subject Thomas Southern, a professor at Bowling Green state University in Ohio, found that "all the studies in social and emotional development show no difference between students who were grade-advanced and those who weren't". (Barko, 1995 p.37) In this respect, Richardson and Benbow, (1990 p.464) stated:

Education acceleration of intellectually advanced students are often used in American schools. Clear benefits are noted for both short-term and long-term academic performance. (E.g., Benbow, 1983: Brody \& Benbow, 1987; Daurio, 1979;) Primarily because of these positive evaluations, acceleration of gifted students is widely endorsed (e.g., Cox, Daniel, \& Boston, 1985; Elkind, 1988).

Unfortunately, parents and educators are often reluctant about acceleration because they worry about the social and 
emotional effects on the child's future. However, meeting the needs of the student should be the most important issue addressed.

The basic premise underlying the use of
acceleration is that the pacing of educational
programs must be responsive to the capacities
and knowledge of individual children (Robinson,
1983 ) : that is, effective teaching involves
"the problem of the match" -students should attempt
new learning at a level slightly exceeding that
already mastered. Acceleration, which involves
the adaptation of curricula design for older
students for use with younger gifted students,
is one productive and practical means of solving
the problem of the match for gifted students
(Richardson \& Benbow, 1990 p.464).

Most schools try to address the needs of the students by enriching their current classwork. This can be successful if a teacher really does provide mind-stretching work.

In a 1992 'study, Sally Reis, an associate professor at The National research Center on Gifted and Talented in Storrs, Connecticut found that 61 percent of third and fourth-grade teachers had no background or training in how to meet the needs of high-ability kids (Barko, 1995).

In spite of strong evidence for the academic benefits of acceleration, it still remains controversial. Resistance to acceleration is often based on preconceived notions, for research has failed to point out the types of acceleration used, what constitutes good social and emotional adjustment, and that most studies lack appropriate reference(control) groups: that is equally gifted nonaccelerants (Pollins, 1983). 
Different Forms of Acceleration

The following describe different forms of accelerated programs:

Early entrance to school: a gifted child who shows readiness to perform "schoolwork enters kindergarten or first grade one or two years earlier than the usual beginning age.

Early entrance to school appears to be a relatively safe accelerative option for bright children. Social and psychological adjustment were neither enhanced nor threatened by the practice. If this were the only option offered a gifted child, it would capitalize on a child's natural intelligence as early as possible and would allow the child to establish a peer group early. As a result, the challenge of making new friends would be encountered only once, instead of with each decision to accelerate. Psychologically, it makes sense that gifted children who are being cognitively challenged from the beginning of their school careers would encounter fewer adjustment problems than those who encounter such a challenge after years of little, required efforts (Rogers and Kimpston, 1992). Grade Skipping, Year Skipping or Placement at a Higher Year Level: A learner is double promoted to skip one or more grade levels. Grade skipping for bright children also appears to be very beneficial. Its greatest research-supported academic and social effects appear to be in the fifth and sixth grades. (Rogers and Kimpston, 1992). 
Nongraded or Multigrade Classroom: A learner is placed in a classroom undifferentiated by grade levels where he or she works through the curricular materials at a pace appropriate to individual ability and motivational level. Bright students in a non-graded or multigrade classroom environment showed substantial, positive academic gains at the elementary grade levels. Although no research on social outcomes could be located, it seems likely that bright children who can move through the curriculum at a comfortable but accelerated pace would not find social rejection so readily as when they stand out as significantly different at one grade level (Rogers and Kimpston, 1992).

Curriculum Compacting: The regular curriculum of any or all subjects is tailored to the specific gaps, deficiencies, and strengths of an individual student. The learners test out or bypass previously mastered skills and content, focusing only on mastery of deficient areas, thus moving rapidly through the curriculum. The single study of social outcomes suggested no differences in socialization. The psychological impact of this option was unclear (Rogers and Kimpston, 1992).

Grade Telescoping: A student's curriculum is reorganized through junior high or high school to shorten the time by one year. Hence, junior high may require two years instead of three, or high school may require three instead of four years for the remainder. Allowing children to progress through a three-year 
curriculum in two years' time showed very positive academic outcomes for both junior and senior high students. This option neither enhanced nor harmed socialization or psychological adjustment (Roger and Kimpston, 1992).

Concurrent Enrollment: A student attends classes in more than one building level during the school year. For example, high school for part of the day and junior high for the remainder. Research suggests no general improvement in academic achievement or social adjustment, despite substantial gains in psychological adjustments (Rogers and Kimpston, 1992).

Subject Acceleration: A student bypasses the usual progression of skills and content mastery in one subject where great advancement or proficiency has been observed. The learner will progress at the regular instructional pace through the remaining subject areas.

In mathematics, subject acceleration resulted in significant positive academic increases for both elementary and secondary students. Socialization was neither harmed nor enhanced; the psychological effects were unclear. Since this form of acceleration accounts for only a small time change in the regular routine, no significant differences in emotional and social well being would be noted (Rogers and Kimpston, 1992). Subject acceleration can be used comfortably for children with specific academic aptitudes, for children whose social maturity is 
questionable and for experimentally determining if the child can adjust to grade skipping (Rimm and Lovance, 1992).

Advance Placement: A student bypasses the usual progression of skills and content mastery in one subject where great advancement or proficiency has been observed. The learner will progress at the regular instructional pace through remaining subject areas. This can occur in elementary, junior high, or high school. The research on Advance Placement did not support significant outcome changes for students once they entered college full-time. Social and psychological outcomes were unclear. This does not mean, however that Advance Placement is not a viable accelerative option for bright high school students. Research shows that participants are not harmed at the college level by having been credited for some courses. The positive effects are that students having been adequately challenged and having been given more time to enroll in courses better suited to their interests and ability levels (Rogers and Kimpston, 1992). Mentorship: A student is placed with a subject matter expert or professional to further a specific interest or proficiency, which cannot be provided within the regular educational setting.

Mentorship showed only small positive academic and adjustment benefits for bright high school students. When a student is matched to someone with more knowledge and equal levels of interest in a specific topic, it makes sense that there 
will be positive outcomes for that student (Rogers and Kimpston, 1992) .

Credit by Examination: Through successful completion of tests, a student is allowed to receive a specified number of collage credits upon entrance to college. (Advance Placement and the College Level Examination Program are two examples.) There appeared to be a strong relationship between testing out of college courses and subsequent college performance in those subject areas. Although socialization was reported as slightly negative, the evidence consisted of one rather weak case study (Rogers and Kimpston, 1992).

Early Admission: A student enters college as a full-time student without completing high school. Students entering college early are usually offered challenging course work that allows more indepth learning (Saylor and Lupkowski, 1992).

Allowing bright students to bypass at least one year of high school to enter college full-time resulted in significantly positive academic outcomes. Socialization and psychological adjustment showed no change. There have been some concerns however, for the high school student who opts for early admission, not completing a high school diploma. Financial constraints, poor health, family crisis, or any combination of circumstances would keep the student from completing college, in which case he or she has no educational certification (Rogers and Kimpston, 1992). 
Problems Involved in Using Acceleration

The literature on academic acceleration of young, gifted children consistently demonstrates a lack of harmful effects. Both early admission and later acceleration have been extensively studied, and no reliable research exists that documents harm (Southern, Jones, and Fiscus, 1989). However, practitioners seem to regard acceleration in general, and early entrance in particular, as risky in serving the needs of the gifted. Southern, Jones, and Fiscus (1989) have suggested several possible reasons why practitioners question the benefits of grade skipping and early admission to school.

Accelerated students will: (a) lose their academic advantage in later school years, (b) experience difficulties in emotional and social development as a result of being relatively young and mediocre in achievement compared to their older classmates, (c) lack the physical and social-emotional maturity to handle the stress of acceleration, and (d) become arrogant or elitists in their attitudes towards others(Daurio, 1979; Kulik \& Kulik, 1984; Stanley, 1980).

As we study gifted children, and problems associated with acceleration and social and emotional development, we must look at the level of IQ of the child. Burks, Jensen, and Terman 1930, p.264 stated:

Someone has said that genius is of necessity solitary, since the population is so sparse at the higher levels of mental ability. However, adult genius is mobile and can seek out its own kind. It is in the case of the child with extraordinary high IQ that the social problem is most acute. If the IQ is 180 , the intellectual level at 6 is almost on a par with the average 11-year-old, and at 10 or 11 is not far from 
that of the average high-school graduate. The inevitable result is that the child of IQ 180 has one of the most difficult problems of social adjustment that any human being is ever called upon to meet.

Research findings most often referenced regarding social adjustments emanate from studies of moderately gifted children. Few research studies have been done on the social and emotional development of the extremely gifted, suggesting that exceptionally gifted (IQ 160) and profoundly gifted (IQ 180+) children tend to have greater problems of social acceptance.

Hollingworth (1926) defined the IQ range 125-135 as "socially optimal intelligence." She found that children within this range were well-balanced, confident and socially effective individuals. She claimed, however, that above the level of 160 IQ the difference between exceptionally gifted children and their age-mates is so great that it leads to special problems of development which are correlated with social needs (Gross, 1992). Exceptionally gifted children appear in the population at a ratio of fewer that one in 10,000 . Research has repeatedly found that these children differ quite substantially from moderately gifted age-peers in many cognitive and effective variables. Because of this, it is not enough to place them in part-time programs, such as resource rooms or pullout, which are designed for moderately gifted students; they require full-time grouping with children closer to their own mental age and levels of socioeffective development. Research suggest that exceptionally and 
profoundly gifted students are served best by a program of radical acceleration incorporating a number of grade-skips appropriately spaced through the student's school career, supplemented with subject acceleration where it is required (Gross, 1992 p.98).

Gross (1992 p.98) found no evidence to suggest that social or emotional problems arise through well-planned and carefully monitored programs of radical acceleration and suggests that we should concern ourselves rather with the maladjusting effects of prolonged educational misplacement.

While a great deal of literature about educational acceleration of gifted students exists, it is apparent that the positive results of acceleration has not been explained or prompted to practitioners in the field.

\section{Benefits of Acceleration}

Successful programs of accelerations have demonstrated significant positive impact on the learning of students (Benbow and Stanley, 1983). Research has revealed the long-term effects of educational acceleration of the gifted (Brody, Assouline, and Stanley, 1990). In addition a study conducted by Brody and Benbow (1987) showed positive results in cognitive development from acceleration, and no negative effects on social and emotional development. They further reported no harmful effects of various forms of acceleration, including grade skipping and advanced 
course taking. Accelerated students generally earned more overall honors and attended more prestigious colleges. In another study by Robinson and Jancos (1986), found similar adjustment patterns for early entrants in comparison to three equally nonaccelerated comparison groups.

Van Tassel-Baska (1986) found that among accelerated students the best predictor of college achievement was early and continued advanced placement course-taking, suggesting that advanced challenging work on an on going basis to be a powerful inducement to achievement later. She had studied acceleration of the various types and at different grade levels and generally reported academic achievement and social adjustment equal to or better than nonaccelerated, similar-ability peers, with no discernible negative effects from the acceleration. Advantages of acceleration include the following: (1) improved motivation, confidence, and scholarship; (2) prevention of lazy mental habits; (3) early completion of professional training; and (4) reduction of the cost of education (Van Tassel-Baska, 1986).

\section{Guidelines for Acceleration}

Educators, parents, and schools must consider acceleration guidelines. The following is a list of recommendations of policies and procedures on acceleration and ability groupings (Van Tassel-Baska, 1992). 
1. Each learner is entitled to experience learning at a level of challenge, defined as task difficulty level slightly above skill mastery. For gifted learners, this implies the opportunity for continuous progress through the basic curriculum based on demonstrated mastery of prior material. In all planned curriculum experiences the gifted students are placed at their instructional level. This level may be determined by diagnostic testing, observation of mastery, or performance-based assessments.

2. Gifted learners should have school-based experiences based on readiness, and exit them based on proficiency. Thus, both early entrance and early exit options should be provided. The gifted learner requires a school system to be flexible about when and where learning takes place. Optimally, a prereading program can best serve some students at age 4; other students may be well served by college opportunities at age 16 . Individual variables must be honored in an overall flexible system of implementation.

3. Some gifted learners may profit from telescoping 2 years of education into one or bypassing a particular grade level. Provision for such advanced placement should be made based on individual student demonstration of capacity, readiness, and motivation. Placement in an actual grade level should be determined by many factors beyond age. Tailoring learning levels, 
as well as bypassing them, is another important way to ensure implementation of this policy (Elkind, 1988).

4. The reason for grouping gifted students should be fundamental to meeting their needs rather than merely as an organizational arrangement. Grouping gifted students is a basic program provision, such as curriculum modification, alternative choice of materials, and learning centers.

5. Grouping strategies for the gifted should remain flexible, based on individual needs of both identified and nonidentified learners. Dyads, small instructional groups, cooperative learning groups, and the seminar model all provide important alternatives for teachers to employ depending on the learning task and the readiness of the learner to engage in it.

6. Gifted learners should have the opportunity to interact with others at their instructional level in all relevant core areas of learning in the school curriculum. Usually, this would imply at least instructional grouping in reading and mathematics at the elementary and special subject area classes and Advanced Placement classes at the secondary level in available course areas. Grouping in science and social studies is also advocated.

7. Gifted learners should be grouped according to special interest areas with other learners who share those interests. Opportunities for small group project work should involve students interested in the same topics or problems. Students then need instruction in the process to be employed in their 
investigation or a model for constructing their own line of investigation.

8. Gifted learners should have the opportunity for independent learning based on both capacity and interest. Not all work with gifted learners need be carried out in-group settings. Their preference for working alone and their capacity to carry out independent work should also be honored and provided for in school settings.

9. There are gifted underachievers that should not be recommended for acceleration (Rimm \& Lovance, 1992).

- children with high IQ's who have many skill deficits

- children with serious behavior problems

- children who absolutely do not want to accelerate even after parent and teacher encouragement

- children who refuse to make efforts in any subject and are unwilling to make a commitment to work after the acceleration

- children from extremely dysfunctional homes

- children whose receiving teachers are so extremely negative about acceleration that it appears that the teacher might cause adjustment to be impossible

10. Gifted students come from all social economic, racial, and ethnic groups. Minority students are and can be served in the context of gifted education. Serving these students 
effectively requires more attention to individual differences and needs. It also requires more acceleration and grouping.

11. Handicapped individuals who are also identified as being potentially gifted, after being provided with a special program focusing on their strengths and fostering the development of higher-level thinking and talents, are able to be successful in the mainstream of the public school. It is imperative that the fields of special education and gifted education work more closely together to better serve gifted handicapped children. 


\section{CHAPTER III}

SUMMARY, CONCLUSIONS, AND RECOMMENDATIONS

\section{Summary}

The purpose of this review of the literature was to examine acceleration to see if it effectively serves gifted education. The review looks at the advantages, disadvantages, and alternatives of acceleration. Finally, the review investigated the guidelines that need to be examined when considering a child for acceleration. The review of the literature addressed five questions to accomplish this purpose.

1. What is the rationale for using acceleration with gifted students?

After surveying 70 years of research on the subject. Thomas Southern, a professor at Bowling Green State University in Ohio, found that "all the studies on social and emotional development show no difference between students who were grade-advanced and those who weren't" (Barko, 1995 p.37). Unfortunately, parents and educators are often reluctant about acceleration because they worry about the social and emotional effects on the child's future.

In spite of strong evidence for the academic benefits of acceleration, it still remains controversial. Resistance to acceleration is often based on preconceived notions, and in fact, 
that research has failed to point out the types of acceleration used, what constitutes good social and emotional adjustment, and that studies lack appropriate reference groups, that is equally gifted nonaccelerants(Pollins, 1983).

2. What are the different forms of acceleration?

Acceleration can be very successful when the correct form is selected. Some of the forms mentioned were:

- early entry of children to formal schooling, secondary schooling or teaching education

- grade skipping, year skipping or placement at a higher level

- non graded or multigrade classroom

- curriculum compacting

- grade telescoping

- concurrent enroliment

- subject acceleration

- advance placement

- mentorship

- credit by examination

- early admission

3. What are the problems involved in using acceleration?

Research finds most often references regarding social adjustments emanated by studies of moderately gifted children. Few studies have researched the social and emotional development of the extremely gifted suggesting that exceptionally gifted (IQ 
160) and profoundly gifted (IQ 180+) children tend to have greater problem of social acceptance (Hollingsworth, 1942).

Researchers find no evidence to suggest that social or emotional problems arise through well-planned and carefully monitored programs of radical acceleration and suggests that we should concern ourselves rather with the maladjusting effects of prolonged educational misplacement (Gross, 1992). While a great deal of literature about educational acceleration of gifted students exists, it is apparent that the positive results of acceleration has not been explained or made available to practitioners in the field.

4. What are the benefits of acceleration?

Studies continue to show positive results in cognitive development from acceleration and no negative effects on social and emotional development. Accelerated students generally earned more overall honors and attended more prestigious colleges. Reported advantages of acceleration include (1) improved motivation, confidence, and scholarship; (2) prevention of lazy mental habits; (3) early completion of professional training; and (4) reduction of the cost of education (Van Tassel-Baska, 1986).

5. What guidelines must be developed when considering a child for acceleration?

These guidelines include the following: 
- Each learner is entitled to experience learning at a level of challenge, defined as task difficulty level slightly above skill mastery.

- Gifted learners should be afforded the opportunity to begin school-based experiences based on readiness and to exit them based on proficiency.

- Some gifted learners may profit from telescoping 2 years of education into one or bypassing a particular grade level.

- Grouping of the gifted should be viewed as a fundamental approach to serving them appropriately rather than merely as an organizational arrangement.

- Grouping strategies for the gifted should remain flexible based on individual needs on both identified and nonidentified learners.

- Gifted learners should have the opportunity to interact with others at their instructional level in all relevant core areas of learning in the school curriculum.

- Gifted learners should be grouped according to special interest areas with other learners who share those interests.

- Gifted learners should have the opportunity for independent learning based on both capacity and interest.

- There are gifted underachievers that should not be recommended for acceleration. 
- Gifted students come from all socio-economic racial, an ethnic groups.

- Handicapped individuals who are also identified as being potentially gifted, need to be served with special programming focusing on their strengths.

\section{Conclusions}

The following conclusions were drawn from this study:

1. The benefits of acceleration can out weigh the social and emotional difficulties if acceleration is handled correctly.

2. Until more longitudinal studies are done, some teachers and parents will continue to bélieve that acceleration is emotionally and socially damaging to gifted students.

3. Several factors including attitude, IQ, and how acceleration is handled play a role in whether acceleration is successful or unsuccessful.

4. Acceleration should be seriously considered for children who meet the guidelines.

\section{Recommendations}

Based on the review of the literature and my own observations of successful acceleration of gifted children, the following recommendations are suggested. 
1. If a child is moderately gifted (IQ 140-160), exceptionally gifted(IQ of 160-180), and profoundly gifted (IQ of 180+) or shows exceptional skills, after adequate testing he or she should be considered for some form of acceleration.

2. Educators should promote positive attitudes toward acceleration of gifted students.

3. Educators have an impact on the attitudes of gifted students who may be accelerated. They need to help students be successful in all aspects of there development.

4. More studies need to be conducted on this topic to determine if any form of acceleration is better than any other. 
References

Alexander, P., \& Skinner, M. (1980), The effects of early entrance on subsequent social and academic development: A follow-up study. Journal for the Education of the Gifted, 3 (3), 147-192.

Barko, N. (1995), Moving up too fast. Parenting, October, pp. $37-38$.

Benbow, C.P. (1983). Adolescence of the mathematically precious. In C.P. Benbow and J.C. Stanley (Eds.), Academic precocity: Aspects of its development (pp.9-29) - Baltimore, MO: Johns Hopkins University Press.

Benbow, C.P., and Stanley, J.C. (Eds.). Academic precocity: Aspects of its development. Baltimore, MO: John Hopkins University Press.

Bloom, B. (1985). Developing talent in young people. New York, Ballantine Books.

Brody, L., Assoaline, S., Stanley, J. (1990). Five years of early entrants: Predicting successful achievement in college. Gifted Quarterly, 34, pp. 138-142.

Brody, L.E., and Benbow, C.P. (1987). Accelerative strategies: How effective are they for the gifted? Gifted Child Quarterly, 31, pp. 105-110.

Burks, B.S., Jensen, D.W., and Terman, L.M. (1930). Genetic studies of genius: Vol. 5: The premise of youth": Follow up studies of a thousand gifted children. Stanford, CA: Stanford University Press.

Cox, J., Daniel, N., and Boston, B.O. (1985). Educating the gifted: Acceleration and enrichment (pp. 15-63). Baltimore, MO: John Hopkins University Press.

Csikszentmihalyi, M. (Ed.). (1988). Optional experiences. New York: Cambridge University Press.

Daurio, S.P. (1979). Educational enrichment versus acceleration: A review of the literature. In W.C. George, S.J. Cohn, and S.J. Stanley (Eds.), Educating the gifted, acceleration, and enrichment (pp. 13-53) . Baltimore, MD: John Hopkins University Press. 
Davis, G.A., \& Rimm, S.B. (1989). Education of the gifted and talented $\left(2^{\text {nd }}\right.$ ed.). Englewood Cliff, NJ: Prentice Hall.

Dweck, C., and Elliot, E.S. (1983). Achievement motivation. In E.M. Htherington (Ed.). Handbook of child psychology (4th ed.) (Vol. 4 pp. 643-691). New York: Wiley.

Elkind, D. (1988)."Point-Counterpoint Education: Acceleration: The Bored and Disinterested Gifted Child: Going Through School Lockstep." Journal for the Education of the Gifted 11, 4:5-8, 32-38.

Gross, M. (1992). The use of radial acceleration in Cases of extreme intellectual precocity. Gifted Child Quarterly, 36, pp.91-98.

Hollingsworth, L.S. (1942). Children above 180 IQ Stanford-Binet. Yonkers, NY: World Book.

Howley, A., Howley, C.B., \& Pendarius, E.D. (1986). Teaching gifted children. Boston: Little, Brown.

Kulik, J.A., \& Kulik, C.C. (1984). Synthesis of research on the effects of the accelerated instruction. Education Leadership, 42 (2) p.84-89.

Pollins, I.D. (1983). The effects of acceleration on the social and emotional development of gifted students. In C.A. Benbow and J.C. Stanley (Eds.), Academic precocity: Aspects of its development (pp.160-179). Baltimore: Johns Hopkins University Press.

Richardson, T.M., and Benbow, C.P. (1990). Iong term effects of acceleration on the social-emotional adjustment of mathematically precious youths. Journal of Educational Psychology. 82(3) . 464-770.

Rimm, S.B., \& Lovance, K.J. (1992). How acceleration may prevent underachievement syndrome. Gifted Child.

Robinson, N.M., and Jancos, P.M. (1986). The psychological adjustment in a college level program of marked acceleration. Journal of Youth and Adolescence, 15, 51-60.

Rogers, K. and Kimpston, R. (1992). Acceleration: What we do vs. what we know. Educational Leadership. 58-61. 
Saylor, M.F., and Lupkowski, A.E. (1992). Early entrance to college: Weighing the options. Gifted Child, 2427.

Sisk, D.A. (1988). "Point-Counterpoint Education: Acceleration: The Bored and Disinterested Gifted Child: Going Through School Lockstep." Journal for the Education of the Gifted II, $4: 5-18,32-38$.

Southern, T, Jones, E. and Fiscus, E. (1989). Practitioner objections to the academic acceleration of gifted children. Gifted Child Quarterly, 33, 29-35.

Stanley, J.C. (1980). On educating the gifted. Educational Research, 9: 8-13.

Van-Tassel-Baska, J., (1986). Acceleration. In J. Maker(Ed.). Critical issues in gifted children (pp. 170196). Rockville, MD: Aspen Publications.

Van-Tassel-Baska, J. (1992). Educational decision making on acceleration and grouping. Gifted Child Quarterly, 36, $68-71$.

Wernick, S. (1992, July 8). Interest renewed in grade skipping as inexpensive way to aid the gifted. The New York Times Education, p. A7. 